\title{
The Eurasian Dry Grassland Group - conserving grassland habitats in the Palaearctic region
}

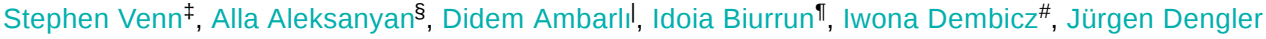 \\ `, Anna Kuzemko", Peter Török”, Michael Vrahnakis^ \\ ‡ University of Helsinki, Helsinki, Finland \\ $\S$ Institute of Botany aft. A.L. Takhtajyan NAS RA/ Department of Geobotany and Plant Eco-Physiology, Yerevan, Armenia \\ | Terrestrial Ecology Research Group, Department for Ecology and Ecosystem Management, Technical University of Munich, \\ Freising, Germany \\ II University of the Basque Country, Bilbao, Spain \\ \# Botanical Garden - Center for Biological Diversity Conservation in Powsin, Polish Academy of Sciences, Warsaw, Poland \\ a Vegetation Ecology Group, Institute of Natural Resource Sciences (IUNR), Zurich University of Applied Sciences (ZHAW), \\ Wädenswil, Switzerland \\ « M.G. Kholodny Institute of Botany, National Academy of Sciences of Ukraine, Umman, Ukraine \\ » MTA-DE Lendület Functional and Restoration Ecology Research Group, Debrecen, Hungary \\ ^Department of Forestry, Wood and Design Sciences, University of Thessaly, Karditsa, Greece
}

Corresponding author: Stephen Venn (stephen.venn@helsinki.fi)

Received: 01 Aug 2019 | Published: 01 Aug 2019

Citation: Venn S, Aleksanyan A, Ambarlı D, Biurrun I, Dembicz I, Dengler J, Kuzemko A, Török P, Vrahnakis M

(2019) The Eurasian Dry Grassland Group - conserving grassland habitats in the Palaearctic region. ARPHA

Conference Abstracts 2: e38711. https://doi.org/10.3897/aca.2.e38711

\begin{abstract}
Grassland ecosystems of Europe comprise a variety of mostly semi-natural habitats, which have developed over long periods of traditional land-use regimes, such as grazing and mowing, and they support a remarkable level of biodiversity. At some scales, the species diversity of these habitats is greater than that of tropical rain forests. Such valuable habitats are currently facing several threats, some natural but mostly anthropogenic, and many of them are threatened with extinction. The Eurasian Dry Grassland Group (EDGG, www.eddg.org) was established in 2008 by scientists, conservationists and others who are involved in the study and conservation of grassland habitats. The organization currently has 1299 members from a total of 64 countries. Since 2004, the EDGG has organized an annual scientific conference in different parts of Europe. Since 2009, the EDGG has also organized international field workshops to collect diversity data on the plant species composition of dry grasslands and related communities in understudied regions of the
\end{abstract}


Palaearctic. These data are collated in the GrassPlot database and used as a resource for collaborative research. We hope to expand this initiative to also include data on arthropod taxa. The next EDGG conference will be held in Bilbao in 2020.

\section{Keywords}

Biodiversity, Land-use, Semi-natural grassland

\section{Presenting author}

Stephen Venn

\section{Presented at}

19thECM poster 